\title{
Microbial and immunological investigations of chronic non-ulcerative blepharitis and meibomianitis
}

\author{
D V SEAL,' J I McGILL, ${ }^{2}$ P JACOBS, ${ }^{3} \mathrm{G}$ M LIAKOS, ${ }^{2}$ AND $\mathrm{N}$ J GOULDING
}

From the 'Division of Communicable Diseases, Clinical Research Centre, Harrow, Middlesex; ${ }^{2}$ Southampton Eye Hospital; and the ${ }^{3}$ Department of Microbiology, Southampton General Hospital.

SUMmaRY Concentrations of tear lysozyme, lactoferrin, ceruloplasmin, IgG, and IgA have been measured by enzyme linked immunosorbent assay (ELISA) in patients with chronic non-ulcerative blepharitis and meibomianitis at the same time as the lid and conjunctivae were cultured for bacteria and fungi by a semiquantitative method. A group of normal controls aged 20 to 80 were similarly sampled, when strains of Staphylococcus epidermidis from their eyes and the patients' eyes were biotyped according to Baird-Parker's scheme. 5\% of blepharitis cases had increased numbers of Staph. aureus present on the lids, compared with only a scanty growth obtained from $5 \%$ of normals. $7 \%$ of blepharitis cases had increased numbers of Staph. epidermidis type VI (coagulase-negative, mannitol-fermenting) present compared with a scanty growth obtained from $6 \%$ of normals. Isolation rates of other types of Staph. epidermidis did not differ from those in normals; no types were associated with meibomianitis. Tear protein profiles were normal in most patients, and there was no increase in tear $\operatorname{IgA}$ or $\operatorname{IgG}$, which is expected with chronic infection. Overall our evidence suggests that in $88 \%$ of cases these lid conditions have an inflammatory aetiology not associated with infection. Staphylococcal isolates often found in the eye usually represent a normal commensal rather than pathogenic flora.

Well recognised types of conjunctivitis and keratitis due to pathogenic bacteria such as Staphylococcus aureus, Streptococcus pneumoniae, Haemophilus influenzae, and Moraxella lacunata have recently been reviewed.' ' However, the reasons why the normal skin flora might develop a pathological role in the causation of chronic infection in the external eye have not been considered recently. Before this can be done, we need to know precisely which organisms are involved. This is particularly relevant when the antibacterial effect of tear fluid is decreased or when the patient is immunocompromised. The possibility of local allergy developing in the external eye must also be considered. ${ }^{34}$ This might arise as a result of increased numbers of an organism on the lid margin as a secondary response in a non-infective condition, or the organism might release its metabolic products to have a toxic effect on the conjunctiva. ${ }^{5}$ These problems are highlighted by the clinical condition of chronic 'staphylococcal' blepharoconjunctivitis, in which there is doubt as to which type of staphyCorrespondence to Dr D V Seal, Clinical Research Centre, Northwick Park Hospital, Watford Road, Harrow, Middlesex HA1 3 UJ. lococcus (Staph. aureus or epidermidis) is involved, and as to whether the disease is due to a toxin, the bacterium, or an allergic response to it, ${ }^{35}$ but is recognised clinically as 'staphylococcus sensitivity'. The clinical diagnosis is further complicated when it is considered that the dry eye is described as being often infected with staphylococci (Staph. aureus or epidermidis), ${ }^{\circ}$ although these bacteria are also part of the commensal flora on the lid margin. In addition, laboratory tests for quantitative dryness of the eye have been most unsatisfactory in the past, relying erroneously on the Schirmer test when incorrect conclusions of 'dryness' have been drawn, since this test is only a crude measure of tear flow.

In order to investigate these problems quantitative bacterial culture has been performed and five tear proteins assayed in patients with chronic nonulcerative blepharitis and meibomianitis. The isolates have been compared with culture results from 66 normal eyes. Staph. epidermidis biotypes have been identified and similarly compared with controls. Three tear proteins (lysozyme, lactoferrin, and ceruloplasmin) have been measured quanti- 
tatively by ELISA in samples of tear fluid, collected simultaneoulsy with the culture swabs, as well as immunoglobulins $\operatorname{IgG}$ and $\operatorname{IgA}$ to investigate whether there is an increase associated with infection. Tear protein analysis was undertaken to compare the tear protein profiles of these patients with those of normal controls of similar age and to differentiate those with profiles of 'questionably dry' or 'dry' eyes.

Although patients with chronic meibomianitis are generally considered to have an inflammatory condition, it was thought appropriate to investigate them similarly, in particular because of the copious amount of secretions that can flow from the meibomian glands on to the lid margin and conjunctiva. Investigations into the secretion and physiology of the meibomian glands have previously been performed by Linton et al. ${ }^{7}$ and recently by Tiffany. ${ }^{~}$

\section{Material and methods}

The external eye was initially examined by biomicroscopic techniques, when patients were placed in clinical groups as defined below. Schirmer's test was carried out on the patients' eyes, after which tear samples were collected on to discs previously weighed accurately in tiny sealed polypropylene pots, specially manufactured for the transport of tear specimens, ${ }^{9}$ when $150 \mu \mathrm{l}$ of buffered saline was added to the disc in the bottle to form a tear eluate. They were transported to the laboratory, where they were held at $-70^{\circ} \mathrm{C}$ until the tear proteins were assayed. The concentration of tear lysozyme, lactoferrin, and ceruloplasmin was assayed in each sample by an ELISA technique using direct binding of eluates or standards to polystyrene microtitre plates and a two-step indirect assay method with peroxidase-conjugated goat antirabbit IgG and rabbit sera specific for each protein." Tear immunoglobulins were measured by ELISA with a direct method using polyvinyl plates and peroxidaseconjugated specific rabbit antihuman $\operatorname{IgG}$ or $\operatorname{IgA}$. Techniques were developed to avoid cross reactions between each 'specific' antiserum and various other proteins, which were capable of causing gross inaccuracy before being investigated and removed."

After tear samples had been collected, both eyes of normal volunteers and patients were cultured for bacteria and fungi by a semiquantitative technique. Three wooden and two wire (pernasal) cotton-wool swabs were used for each eye. The lids were sampled first with the wooden swabs, which were each dipped into sterile distilled water. They were each rubbed along the lid from the lateral canthus to the punctum. The first swab was plated out on to a chocolate agar plate; the second was placed into a bijou bottle containing $0.5 \mathrm{ml}$ distilled water, which preserves fungal spores; the third was placed into another bijou bottle which contained olive oil medium for culturing Pityrosporum sp. The conjunctivae were cultured after the lids with the wire swabs. They were similarly dipped into distilled water, but then rubbed along the conjunctiva from lateral canthus to punctum. The first was plated out on to a chocolate agar plate, and then placed into a new bijou bottle containing $0.5 \mathrm{ml}$ distilled water; the second was placed into a new bijou bottle of olive oil medium. Plates were incubated at $37^{\circ} \mathrm{C}$ in $\mathrm{CO}_{2}$ for 48 hours with chocolate agar, as it supports the growth of the normal commensal flora as well as the recognised pathogens. Fluid enrichment media were not used, as we wished to establish the predominant bacterial flora on a semiquantitative basis. All plates were inoculated in the clinic in a standard manner. The amount of growth for each culture was recorded as $+1-$ (up to five colonies), + (up to 10 colonies), or ++ (10 to 100 colonies).

Bacterial colonies were identified by standard laboratory techniques. "Staphylococci were differentiated by the tube coagulase test into Staph. aureus or epidermidis, which were positive and negative respectively. Staphylococcal colonies isolated were further subcultured on mannitol salt (7.5\%), agar (Oxoid CM85), and phenolphthalein phosphate 1\% agar (Oxoid SR 31) to test them for mannitol fermentation, salt tolerance, and phosphatase production-simple Baird-Parker classification ${ }^{12}$ for types I to VI (Table 1). For this study no distinction has been made between Baird-Parker types II and III, considered together as one group, and types IV and V, considered as the second group. Type VI strains, considered as the third 'epidermidis' group, were further typed biochemically and tested for their susceptibility to lysis by staphylococcal phages at the

Table 1 Differentiation of Staphylococcus aureus and Staph. epidermidis by simple Baird-Parker's scheme

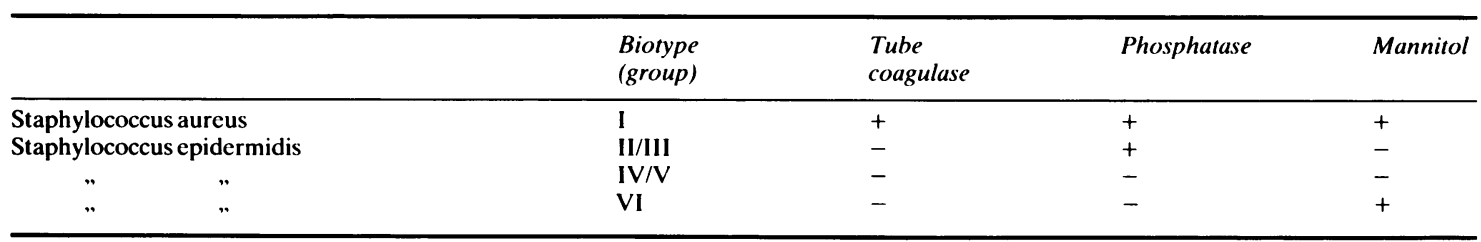




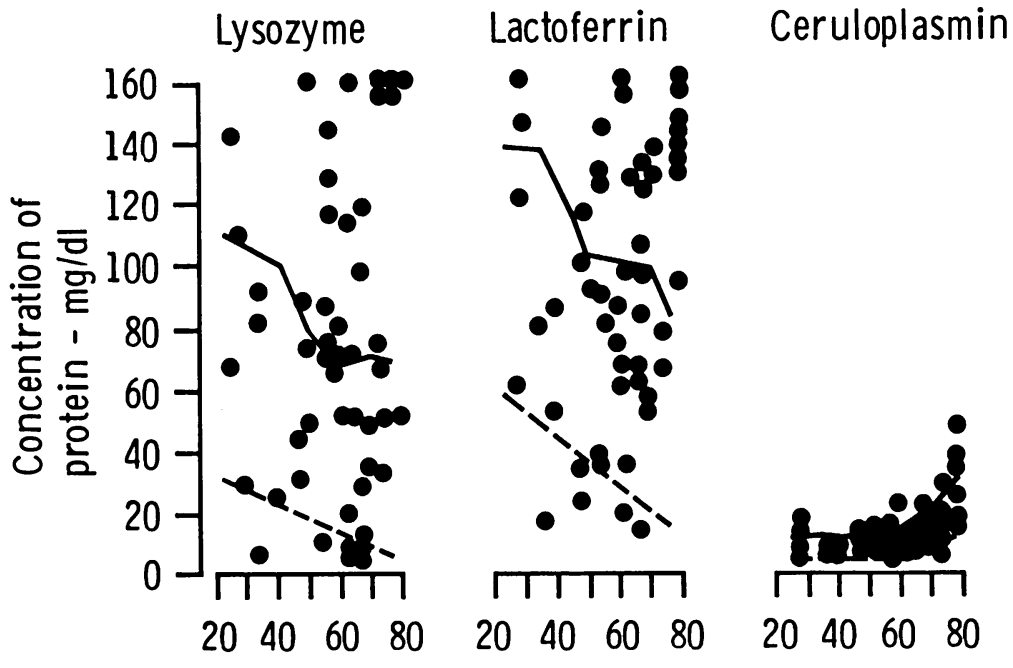

Fig. $1 \quad$ Tear protein levels in
chronic non-ulcerative blepharitis. (SI conversion: $m g / d l \times 0.01=g / l$.)

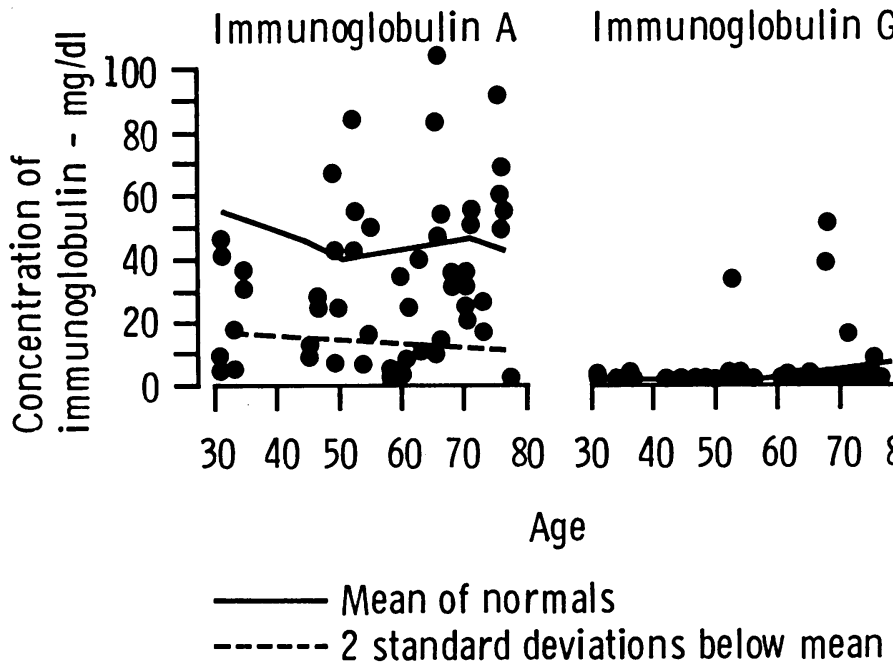

Division of Hospital Infection, Central Public Health Laboratory, Colindale, London NW9.

The distilled water bijou bottles were kept at room temperature and subcultured within 24 hours onto Sabouraud's agar, both with and without chloramphenicol. Colonies were identified morphologically and microscopically with lactophenol blue stain. Candida albicans was confirmed by the 'germ tube' test. Aspergillus and Penicillium species were identified by their conidiospores and pigment production. The Olive oil media were incubated on receipt at $37^{\circ} \mathrm{C}$, as they were suitable for both transport and culture. They were then incubated for seven days at $35^{\circ} \mathrm{C}$. Presumptive identification of a Pityrosporum $\mathrm{sp}$. was made by microscopical observation of their characteristic round bodies. This yeast-like fungus will grow only in media which contain fatty acids and does not grow on Sabouraud's agar alone. These two techniques, for fungal and pityrosporum culture, are qualitative and not quantitative. Because the isolation rate of fungi was expected to be lowapproximately $3 \%^{13}$-a qualitative study seemed preferable.

PATIENTS

Both eyes of 33 normal volunteers were sampled by our modified Schirmer's test,${ }^{14}$ tear protein assay, and microbial culture. Both eyes of 26 patients with chronic non-ulcerative blepharitis were similarly sampled, as were 13 patients (26 eyes) with meibomianitis as well as 19 patients (38 eyes) in whom the clinical diagnosis of chronic blepharitis and possible dryness of the external eye was considered likely. 


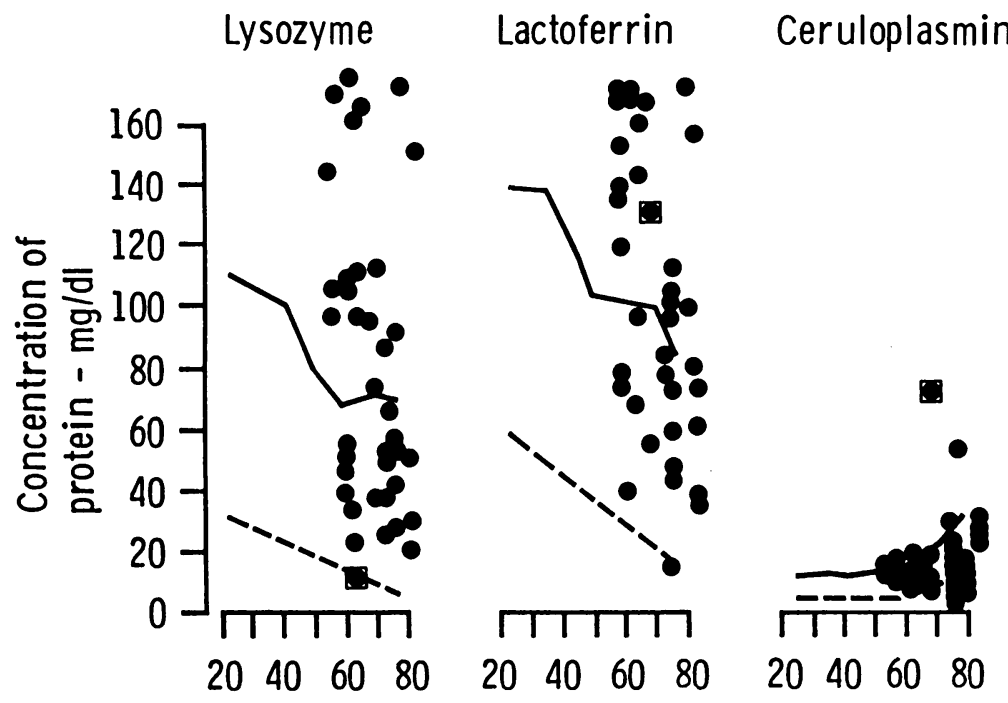

Fig. 2 Tear protein levels in 'blepharitis and possible dryness.' (SI conversion: $m g / d l \times 0 \cdot 01=g / l$.)

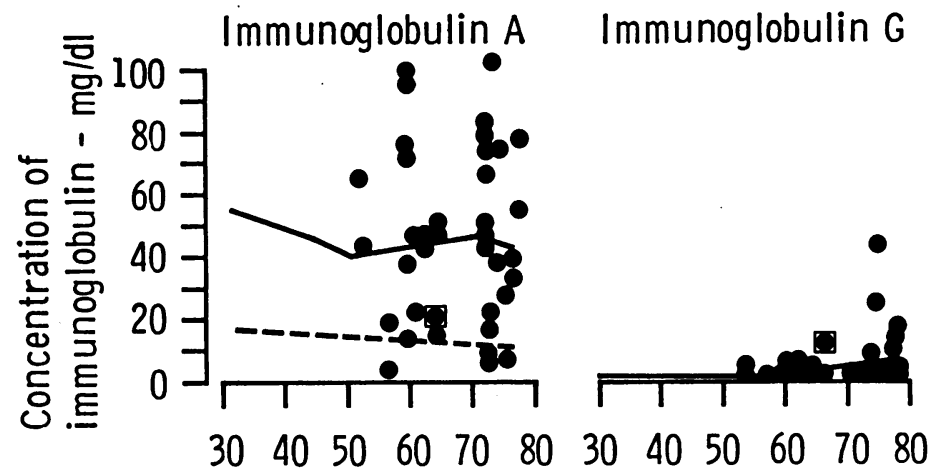

Age

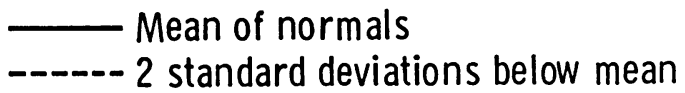

A patient was deemed to have non-ulcerative blepharitis if the lid margins were crusted, scaley, or oily and the hair follicle bases were often infiltrated. Meibomianitis was described as present when the meibomian gland orifices were stenosed, infiltrated, and often pouting away from the lid margin. They were often enlarged and visible beneath the conjunctiva. There was an associated frothy discharge present along the lid margins, which was often more apparent after the installation of rose Bengal. In both conditions associated tear film abnormalities included an uneven tear film, often filled with mucous threads, and debris with a decreased breakup time, and punctate erosions (staining with fluorescein) or keratopathy (staining with rose Bengal), particularly along the inferior conjunctiva and cornea adjacent to the lid margins. If the tear film changes were marked, a dry eye state was said to exist, with a decreased marginal tear strip and precorneal tear film. Punctate keratopathy, as stained with rose Bengal, extended over all the epithelial surface in the interpalpebral fissure, particularly when the Schirmer test gave less than $10 \mathrm{~mm}$ wetting in five minutes.

A papillary conjunctival reaction was often present. In the suspected dry eye patient there was a variable punctate keratopathy over the conjunctiva and cornea in the interpalpebral fissure together with some or all of the tear film changes described above. Symptoms of non-ulcerative blepharitis included itching or burning of the lids and stinging eyes. If tear film changes coexisted, the symptoms included burning, gritty eyes and photophobia with 'reflex tearing.' 
Fig. 3 Tear protein levels in meibomianitis. (SI conversion: $m g / d l \times 0.01=g / l$.)
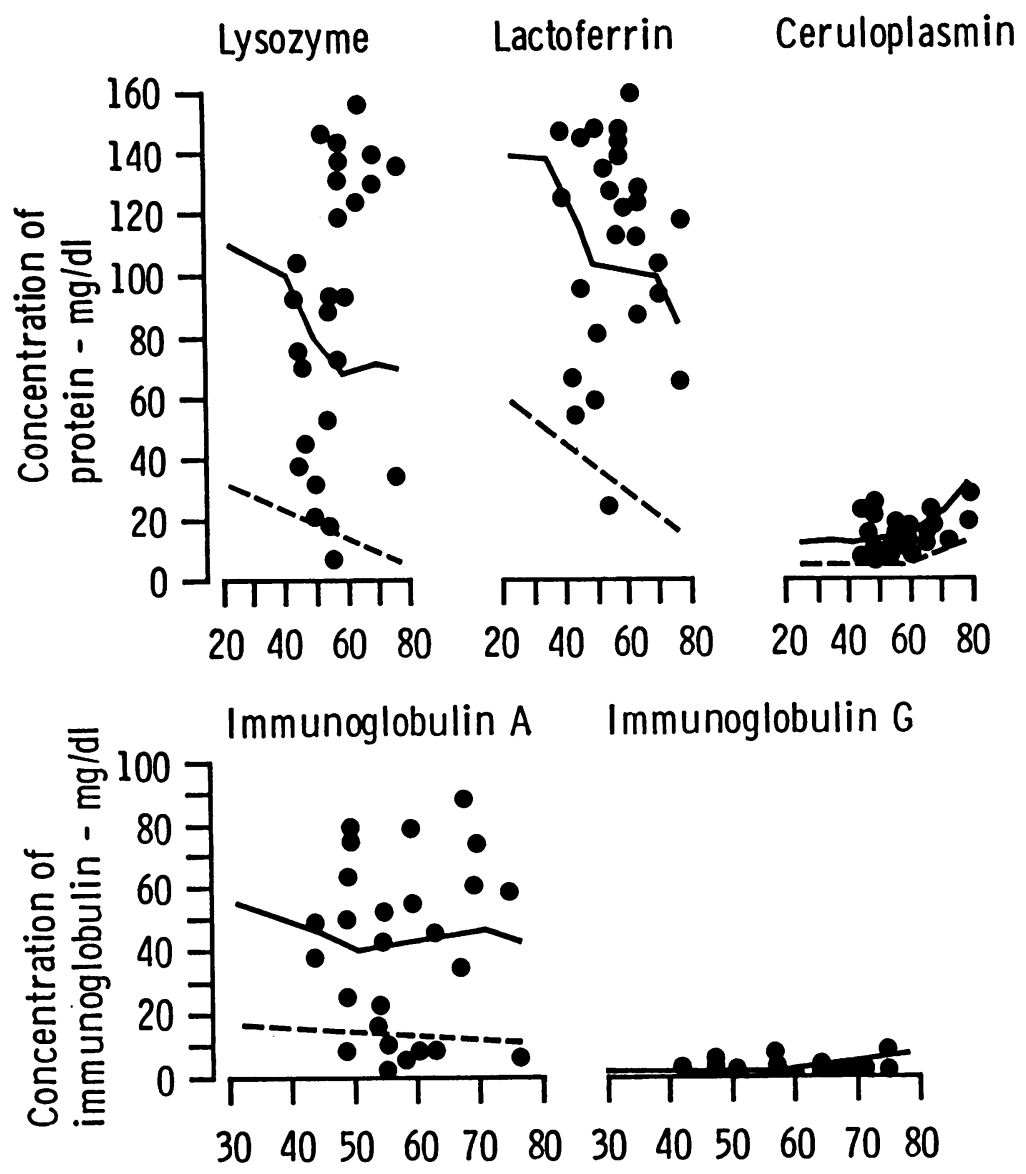

Age

Mean of normals

2 standard deviations below mean

\section{Results}

Concentrations of tear lysozyme, lactoferrin, ceruloplasmin and immunoglobulins IgG and IgA are given in Figs. 1 to 3 for each patient group studied. The mean normal values, and a $95 \%$ confidence limit of 2 standard deviations below the mean, were previously studied"s and are shown in the figures, where the expected changes in concentration with age for each protein can be directly compared with the patients' levels. No significant differences were found between mean concentration values for each protein of the patient groups studied, and normal mean values as given. However, five eyes in the chronic blepharitis group showed evidence of being "questionably dry, ${ }^{14}$ with low levels of tear lysozyme and lactoferrin

Table 2 Modified Schirmer test results for each patient group and normals

\begin{tabular}{|c|c|c|c|c|}
\hline Clinical group & Meanage & $\begin{array}{l}\text { Sex ratio } \\
(M / F)\end{array}$ & $\begin{array}{l}\text { Mean Schirmer } \\
\text { result }(\mathrm{mm})\end{array}$ & $\begin{array}{l}\text { Mean Schirmer value } \\
\text { for age } 15\end{array}$ \\
\hline Chronic non-ulcerative blepharitis & 57 & $13 / 13$ & 21 & 21 \\
\hline Blepharitis and possible dryness & 69 & $2 / 17$ & 13 & 17 \\
\hline Meibomianitis & 57 & $8 / 5$ & 22 & 21 \\
\hline
\end{tabular}

There was no significant difference between the mean Schirmer results gained and the normal mean values expected for each age group. 
Table 3 Qualitative bacteriology for each patient group and normals

\begin{tabular}{|c|c|c|c|c|}
\hline & \multicolumn{4}{|c|}{ Lid flora (\% isolations in each group) } \\
\hline & $\begin{array}{l}\begin{array}{l}\text { Normals } \\
\text { eyes }\end{array} \\
(n=66)\end{array}$ & $\begin{array}{l}\text { Blepharitis } \\
(n=52)\end{array}$ & $\begin{array}{l}\text { Blepharitis } \\
\text { and possible } \\
\text { dryness } \\
(n=38)\end{array}$ & $\begin{array}{l}\text { Meibomianitis } \\
(n=26)\end{array}$ \\
\hline Staph. aureus (I) & 5 & 8 & 9 & 12 \\
\hline - epidermidis (II/III) & 48 & 42 & 34 & 40 \\
\hline — cpidermidis (IV/V) & 8 & 22 & 14 & 16 \\
\hline - epidermidis (VI) & 6 & 10 & 12 & 0 \\
\hline Micrococcus & 21 & 17 & 13 & 22 \\
\hline Streptococcus viridans & $\mathbf{0}$ & 0 & 3 & 0 \\
\hline Diphtheroids & 31 & 13 & 5 & 26 \\
\hline Neisseria sp. & 3 & 0 & 0 & 0 \\
\hline Haemophilus sp. & 2 & 0 & 0 & 0 \\
\hline Moraxella sp. & 0 & 2 & 0 & 0 \\
\hline Coliforms & 5 & 0 & 0 & 0 \\
\hline Pityrosporum sp. & $7 \cdot 5$ & $6 \cdot 5$ & 0 & $19^{*}$ \\
\hline Nogrowth & 17 & 6 & 8 & 13 \\
\hline
\end{tabular}

*Significant difference from normals at 0.05 level.

(shown in Fig. 1. lying greater than 2 standard deviations below the mean) but with normal levels of ceruloplasmin.

The mean ages, sex and Schirmer results are given in Table 2.

Table 3 gives the results of the various types of bacteria, including subtypes of Staph. epidermidis, isolated from each condition.

The results of conjunctival cultures were usually similar to those for the lid flora but occurred in a lower percentage of patients. In normal volunteers the conjunctivae were 'sterile' in only $17 \%$, while conjunctival cultures yielded a different biotype of Staph. epidermidis from lid cultures in only $1 \%$. Two different biotypes (groups) of Staph. epidermidis were simultaneously isolated from $8 \%$ of normals, $4 \%$ of patients with meibomianitis, and $21 \%$ of patients with blepharitis. Isolates of Staph. epidermidis biotype VI were later confirmed with further biochemical tests. They were divisible into three subtypes, but there was no association between any one subtype and the clinical group investigated. All isolates of biotype VI failed to show susceptibility to lysis by phage typing. There were no occasions when the conjunctival cultures gave a greater amount of growth than did the lid cultures, so it is considered that the conjunctival isolations made represented contamination of the conjunctiva by the lid margin flora.

Table 4 gives the quantitative bacteriology results

Table 4 Quantitative bacteriology results for staphylococci isolated from lids and conjunctivae

\begin{tabular}{|c|c|c|c|c|c|c|c|c|c|}
\hline & & \multicolumn{8}{|c|}{$\%$ Isolations in each group } \\
\hline & & \multicolumn{2}{|c|}{$\begin{array}{l}\text { Normal } \\
\text { eyes }\end{array}$} & \multicolumn{2}{|c|}{ Blepharitis } & \multicolumn{2}{|c|}{$\begin{array}{l}\text { Blepharitis and } \\
\text { possible dryness }\end{array}$} & \multicolumn{2}{|c|}{ Meibomianitis } \\
\hline & & Lid & Conj. & Lid & Conj. & Lid & Conj. & Lid & Conj. \\
\hline \multicolumn{10}{|l|}{ Staph. aureus } \\
\hline \multirow[t]{3}{*}{ Biotype I } & $+1-$ & 5 & 2 & 2 & 2 & 6 & - & 21 & - \\
\hline & + & - & - & 4 & 4 & - & 3 & - & - \\
\hline & ++ & - & - & 2 & - & 3 & - & - & - \\
\hline \multicolumn{10}{|l|}{ Staph. epidermidis } \\
\hline \multirow[t]{3}{*}{ Biotype II/III } & $+1-$ & 3 & 12 & 2 & 2 & 3 & 6 & - & 4 \\
\hline & + & 35 & 20 & 36 & 32 & 28 & 11 & 40 & 20 \\
\hline & ++ & 10 & 2 & 4 & - & 3 & - & - & - \\
\hline \multirow[t]{3}{*}{ Biotype IV/V } & $+1-$ & - & 5 & 2 & - & - & 3 & - & 4 \\
\hline & + & 6 & 9 & 20 & 12 & 14 & - & 16 & 12 \\
\hline & ++ & 2 & 一 & - & - & - & - & - & - \\
\hline \multirow[t]{3}{*}{ Biotype VI } & $+1-$ & 6 & 一 & 2 & 2 & 6 & 6 & - & - \\
\hline & + & - & 2 & 8 & 2 & 3 & - & - & - \\
\hline & ++ & - & - & - & - & 3 & - & - & - \\
\hline
\end{tabular}


Table 5 Mycology results for each patient group and normals

\begin{tabular}{|c|c|c|c|}
\hline Clinical Group & $\begin{array}{l}\text { Numbers with } \\
\text { Pityrosporum sp. } \\
\text { isolated }\end{array}$ & $\%$ & $\begin{array}{l}\text { Significance } \\
\text { level }\end{array}$ \\
\hline \multicolumn{4}{|l|}{ Pityrosporumsp. } \\
\hline Normals & $3 / 66$ & $4 \cdot 3$ & - \\
\hline Blepharitis & $5 / 52$ & $9 \cdot 6$ & Not significant \\
\hline $\begin{array}{l}\text { Blepharitis with } \\
\text { possible dryness }\end{array}$ & $1 / 38$ & $2 \cdot 6$ & Not significant \\
\hline $\begin{array}{l}\text { Meibomianitis } \\
\text { Other fungi }\end{array}$ & $4 / 26$ & $15 \cdot 3$ & $0 \cdot 05$ \\
\hline Normals: & \multirow{2}{*}{\multicolumn{3}{|c|}{ No fungi isolated }} \\
\hline \multirow[t]{3}{*}{ Blepharitis: } & & & \\
\hline & \multicolumn{3}{|c|}{ Candida parapsilosis (lid+conjunctiva) } \\
\hline & \multicolumn{3}{|c|}{ Aspergillus flavus (lid) } \\
\hline Meibomianitis: & \multicolumn{3}{|c|}{ Rhizopus sp. (lid) } \\
\hline
\end{tabular}

for staphylococci isolated from lids and conjunctivae.

Table 5 gives the results of fungi isolated from each condition.

\section{Discussion}

Using a semiquantitative culture method we found that $5 \%$ of blepharitis cases had increased numbers of Staph. aureus on the lids, while $7 \%$ had increased numbers of Staph. epidermidis type VI. Further, patients with blepharitis had a more frequent occurrence than normals ( $21 \%$ versus $8 \%$ ) of two different biotypes of Staph. epidermidis being isolated simultaneously from the lids. We found similar numbers of Staph. epidermidis types II/III and IV/V in patients as in normals, and even found heavier growths in the normals than the patients, so that these organisms are unlikely pathogens. We failed to find a pathogenic bacterium in $88 \%$ of cases of blepharitis and all meibomianitis cases. It is thus quite likely that many reported isolations of staphylococci in association with blepharitis ${ }^{516}$ or dry eyes ${ }^{6}$ also represent commensal and not pathogenic flora, giving rise to much confusion in the literature and to misunderstanding of the pathogenesis of some external eye diseases. Our findings of increased numbers of coagulasenegative mannitol-fermenting staphylococci (Staph. epidermidis type VI) in some cases of blepharitis agree with those of Okumoto et al. ${ }^{17}$

Investigation of individual patients is best performed with the full quantitative culture techniques of conjunctival sponge discs ${ }^{18}$ or soluble alginate swabs, ${ }^{11}$ rather than ordinary swab techniques, when accurate enumeration can be attained of all the bacteria present, and the presence can be detected of increased numbers of a particular organism. Absolute numbers of bacteria have been established with the latter method for the normal eye.
Pityrosporum sp. has been isolated from cases of meibomianitis significantly more often, at the 0.05 level, than from normals. However, this fungus is present in large numbers on the normal scalp, and it has probably occurred more often because of copious meibomian secretions on the lid margin containing fatty acids, which support its growth. Both Candida and an Aspergillus sp. were isolated from patients with blepharitis on four occasions but not from normals. Whether they were present because of the inflammation on the lid margin is not clear, nor is it known whether they were present as transient flora. They were, however, isolated from only $4.4 \%$ of eyes with blepharitis.

Most cases $(88 \%)$ of blepharitis and all of meibomianitis were uninfected and did not change tear immunoproteins as measured here. The effect on the tear film and association with debris in the film itself, such as punctate keratopathy of the conjunctiva, particularly along the lid margin, must be due to disturbance of the tear film components themselves, perhaps due to the excessive secretions from the lid margin. These effects include a disturbance of the tear film oily layer, the result of the blepharitis or meibomianitis leading to tear spillage from loss of the lid's tear-retaining properties, increased tear evaporation, and osmolarity. In the past, exotoxins from Staph. epidermidis ${ }^{5}$ have been thought to play a part in producing the symptoms and signs that occur in these conditions but this now seems unlikely.

Comparison of tear protein profiles between each group and normals has failed to show a significant difference, though six eyes in the blepharitis group were 'questionably dry. ${ }^{14}$ The group of patients with 'blepharitis and possible dryness,' diagnosed on clinical examination alone, has been shown to have normal lacrimal gland function with normal tear lysozyme and lactoferrin levels, which demonstrates the difficulty of diagnosing early dryness of the external eye. Alternatively, localised dryness in the tear film is due to excess tear evaporation or mucin abnormality, with no alteration of the constituents of the watery layer of the tear film as sampled. The assays of $\operatorname{IgG}$ and $\operatorname{IgA}$ showed no increase, compared with normal controls, that would be expected if chronic infection is present.

McCulley et al. ${ }^{20}$ have recently investigated the causes of blepharitis and suggested a classification including staphylococcal, seborrhoeic, mixed seborrhoeic/staphylococcal, mixed seborrhoeic/ meibomian, and primary meibomianitis. They concluded that the role of staphylococci needs to be reassessed, in particular its pathogenicity and toxin production, which relates to studies performed in the 1930s and 1940s, as well as the effect of its release of 
lipases. Keith ${ }^{21}$ has suggested that the condition is primarily seborrhoeic and that excess meibomian secretion is mainly responsible for the inflammation, although he grew staphylococci from one third of his cases-but did not compare them with controls. Baum $^{16}$ suggests that staphylococci represent the most important cause of blepharitis, though he reports successful treatment of some cases with topical steroids, which usually result in staphylococcal infections becoming worse. Cory et al. ${ }^{22}$ investigated blepharitis in rosacea, including fatty acid secretion from the meibomian glands, but were unable to detect any differences compared with controls. There is a need to measure the different mediators of the inflammatory process in the tear film, and to identify the type of inflammation involved, as well as to consider the use of topical treatment with anti-inflammatory drugs other than steroids.

We are very grateful for the grants received from the National Institute for Prevention of Blindness and from Wessex Regional Health Authority, which funded Mr Liakos and Dr Goulding respectively. We are also grateful to Dr $R$ Marples for examining our strains of Staph. epidermidis type VI in Central Public Health Laboratory, Colindale, and to Professor P Watt for providing space for Dr Goulding in the Microbiology Laboratory of Southampton Medical School. We also thank Miss D Badiani for valuable assistance.

\section{References}

1 Fedukowicz, HB. External infections of the eye. 2nd ed. New York: Appleton-Century-Crofts, 1978.

2 Seal DV, Barrett SP, McGill J. Acute bacterial infection of the external eye. BrJ Ophthalmol 1982; 66: 367-60.

3 Jones BR. Allergic disease of the outer eye. Trans Ophthalmol Soc UK 1971; 91: 441-7.

4 Easty D. Allergic Disease of the eye. Hospital Update 1984; 10: 653-64.
5 Smolin G, Okumoto M. Staphylococcal blepharitis. Arch Ophthalmol 1977; 95: 812-6.

6 Wright P. Diagnosis and management of dry eyes. Trans Ophthalmol Soc UK 1971; 91: 119-28.

7 Linton RG, Curnow DH, Riley WJ. The meibomian glands: an investigation into the secretion and some aspects of the physiology. Br J Ophthalmol 1961; 45: 718-23.

8 Tiffany JM. The role of meibomian secretion in the tears. Trans Ophthalmol Soc UK in press.

9 Seal DV, Mackie IA, Coakes RL, Farooqi B. Quantitative tear lysozyme assay: a new technique for transporting specimens. $\mathrm{BrJ}$ Ophthalmol 1980; 64: 700-4

10 Seal DV. Pathophysiology of bacterial infection in the external eye. MD thesis, University of London, 1984.

11 Cowan ST, Steel KJ. Manual for identification of medical bacteria. 2nd ed. London: Cambridge University Press, 1974.

12 Marples RR. Taxonomic studies of staphylococci and micrococci. In: Jeljaszewicz J, ed. Staphylococci and staphylococcal diseases. Stuggart, New York: Fischer 1981: 9-13.

13 Williamson J, Gordon AM, Wood R, Dyer A McK, Yahya OA. Fungal flora of the conjunctival sac in health and disease. $\mathrm{Br} J$ Ophthalmol 1968; 52: 127-37.

14 Mackie IA, Seal DV. The questionably dry eye. BrJ Ophthalmol 1981; 65: 2-9.

15 McGill JI, Liakos GM, Goulding N, Seal DV. Normal tear protein profiles and age-related changes. Br J Ophthalmol 1984; 68: 316-20.

16 Baum JL. Ocular infections. N Engl J Med 1978; 229: 28-31.

17 Okumoto M, Smolin G, Somy M, Zhang WH. The clinical significance of coagulase-negative staphylococci. Am J Ophthalmol 1984 in press.

18 Hadley WK, Aronson SB, Goodner EK. Quantitative conjunctival bacteriology. Arch Ophthalmol 1973; 90: 386-8.

19 Cagle GD, Abshire RL. Quantitative ocular bacteriology: a method for the enumeration and identification of bacteria from the skin-lash margin and conjunctiva. Invest Ophthalmol Visual Sci 1981; 20: 751-7.

20 McCulley JP, Dougherty JM, Deneau DG. Chronic blepharitis: classification and mechanisms. Proceedings of immunology of the eye; workshop: III. Suran A, Gery I, Nussenblatt RB, eds. Immunology Abstracts 1981; special suppl: 55-72.

21 Keith CG. Seborrhoeic blepharo-kerato-conjunctivitis. Trans Ophthalmol Soc UK 1967; 87: 85-103.

22 Cory CC, Hinks W, Burton JL, Shuster S. Meibomian gland secretion in the red eyes of rosacea. BrJ Dermatol 1973; 89: 25-7. 